\begin{tabular}{|l|c|c|}
\hline Word and Text & Vol. XI & $42-54$ \\
A Journal of Literary Studies and Linguistics & December / 2021 & 42 \\
\hline
\end{tabular}

\title{
The Vulnerability of Animal Life in Derrida's Philosophy
}

\begin{abstract}
Patrick Llored
Université de Lyon (Centre de recherche en éthique animale appliquée)

E-mail: 1loredpatrick@neuf.fr

Abstract

Derrida has been preoccupied by the animal from the beginning to the end of his life. It can be found from the first to the last texts, but its presence is always subjected to new formulations and explications, as if the question of the animal in Derrida's thinking could never be exhausted: indeed, nothing and nobody can seemingly exhaust it... Our reading takes this inexhaustibility as its starting point in order to examine one of the last concepts reworked by Derrida towards the end of his life, to which his readers have hitherto paid scant attention: the concept of vulnerability. This article probes into the possibility for this concept to allow us to reread in depth Derrida's relevant texts as a unified body of works, albeit without claiming to exhaust their meaning(s).
\end{abstract}

Keywords: vulnerability, (sense of) touch, haptocentrism, life-death, inability/unpower [impouvoir], animal suffering, Aristotle, Jeremy Bentham

\section{Introduction}

Reading and understanding the problem of vulnerability in Derrida is a difficult task owing first to the fact that the philosopher's writings on the question of the animal are complex. Several intellectual traditions feed Derridean thinking on animality as well as vulnerability. Although Derrida has dedicated very few texts - a mere few pages, actually - to vulnerability, the fact remains that he has always faced this question indirectly, either through the issue of animal suffering, with which he has dealt extensively, or through confrontation with the great thinkers on the question of the animal (from Aristotle to Heidegger via Descartes, among many others). Hence the difficulty in attempting to identify a thinking about vulnerability in what should rightly be called an 'animal philosophy', without however reducing the latter to a set of theses. Our reading can thus be indirect only and, in order to think through vulnerability in Derrida, it will lead us to adopt a potentially surprising angle: animal touch. Our main reading hypothesis lies in trying to establish a close link between Derrida's thinking about touch and about vulnerability.

\section{Animal Vulnerability and Touch}

Indeed, one of the original features in Derrida's animal philosophy is to think through the problem of vulnerability in close connection with that of touch. Why is touch so important in relation to the issue of vulnerability? Is touch like any other sense in animal life? Should it not rather be thought of as the condition of existence of all the 
other senses? Or, more fundamentally still, is it not the sense of vital necessity and therefore of the life of the living, and, in this capacity, does it not play a key role in the Derridean thinking on the animal's vulnerability?

The somewhat radical and uncommon thesis which we wish to defend here, by relying on Derrida's animal philosophy, is that touch is properly speaking not a sense, or more precisely that it constitutes the sense of senses and in this capacity plays a fundamental role in the question of vulnerability in animal life in Derrida. Seldom have philosophers granted the animal this right to touch and consequently truly thought through the complex, fundamental question of vulnerability, especially in the continental philosophical tradition, which makes the problem of animal suffering possible, the subject of any animal ethics worthy of this name. Among them is Aristotle, whose interest in such a question will enable us to better understand Derrida's contribution to the vast question of the links between touch and the vulnerability of animal life. Although Aristotle's philosophy of the living is in no way an animal ethics and although it cannot be understood outside a biological naturalism which basically reduces animal touch to a primordial physiological function, it is still important to underline that he nonetheless grants touch a central role in the animal for, according to him, it is the only sense which is indispensable to the existence of the animal living being as such. Aristotle does not make an ethical principle out of it; it is just a scientific observation which Derrida will take very seriously and turn into something else than an empirical phenomenon. In his De Anima, Aristotle writes that '[i]t is evident [...] that of necessity animals deprived of this sense [of touch] alone will die. For nothing having this can fail to be an animal, nor does what is an animal need any sense other than this. ${ }^{1}$ Aristotle's thesis is very radical since it makes of touch the only sense indispensable to the existence of the animal living being. Basically, the animal living being can be thought through, so Aristotle says, only if one takes into account the existence of this sense as the condition of the animal's very existence. Thus, for the animal, touch relates to a vital necessity without which its very life would be called into question. Hence the close link not only between touch and the animal's life but also between touch and its death as soon as, if touch is indeed what makes the life of the living, if there is indeed a 'coextensivity' of life and touch, as Derrida indicates while echoing a key idea of Aristotle's, Aristotle's major discovery is to have put touch to the 'test of death', more exactly to have made of this sense nothing short of a question of life and death. Here is the way in which Derrida defines the problem and integrates it into a reflection on vulnerability:

Aristotle measures this essential coextensivity of animal life and touch; he also explains it by putting it to the test of death. When an animal is deprived of sight, hearing, or taste, it does not necessarily die. Should it come to a lack of touch, however, it will die without delay. (This follows the set of distinctions recalled earlier. Among the senses, touch is an exception, because it has as its object more than one quality - in truth, it potentially has all sensible qualities.) Conversely (but it is the other side of the same phenomenon), animals also die when an excessive intensity of touch touches them. Tangible excess, 'hyperbole,' comes to destroy the organ of this touching, 'which is the essential mark of life' [...] Couldn't one say that this measure, this moderation of touch, remains at the service of life

\footnotetext{
${ }^{1}$ Aristotle, De Anima, trans. and intr. Christopher Shields (Oxford: Clarendon, 2016), 435b4-6.
} 
to the sole extent, precisely, that some kind of reserve holds it on the brink of exaggeration ${ }^{2}$

Therefore, the importance of touch for Derrida cannot be understood independently of the aporia to which it is constantly submitted, for if all animal life is necessarily dependent on touch, at the same time and at the same place, death itself can come from touch when the latter becomes dominant, that is to say, violent, in the form of an 'excessive intensity' which implies that this 'hyperbole' of the sensible can take the form of an auto-immunitary process which turns against the animal itself. One should not hesitate to speak of suicide to evoke this life which self-destroys. This is why one can say that, like no other sense, touch obeys a complex logic which Derrida has elucidated, a logic which has to do with the pharmakon, at once 'remedy' and 'poison', a central concept in Derrida's animal philosophy. Indeed, this peculiar sense that touch is in the life of the animal is truly the one which institutes at its heart what Derrida has always called 'life-death', ${ }^{3}$ which is inseparable from an ethics of vulnerability founded on the concept of 'reserve' through which it draws its resources, not from formal and normative rules external to it but rather from the very body of the animal thought through in its complexity as a living being thus understood in terms of a pharmacological interpretation of life.

Touch appears therefore as the sense of encounter between the human as well as non-human living insofar as it allows each of them without exception to be inscribed within a space in which the borders between the 'self' and the 'non-self' are elaborated, from which contact, hence the encounter as event, become possible:

Following Aristotle and those beyond him, let us suppose that the haptical, unlike the other senses, is coextensive with the living body. Let us further suppose that eating, as Aristotle also says, has to do with touch. What does incorporation become, then, and what does it signify, in concert with mourning? Still a living moment of life? Of course - how could it be otherwise? Still, one would have to include death within life. Would this living moment of life be an interiorization or an expulsion? A becoming-tangible of the untouchable or on the contrary an idealization, a spiritualization, an animation that produces an intangible becoming of the tactile body, of the touching and touched?

In what way would this matrix of questions give birth to the question of the world? And to the question of finitude? For the haptical is not just a sense among others, and in a way it is not even a sense, sensu stricto (we'll come back to this) because, to every finite existence, it recalls what is coming-so as to present it with something, whatever it may be, whatever being it may be, but while marking, with the gift of this presentation, the limit at which or from which the presentation announces itself. ${ }^{4}$

Consequently, if this coextensivity of touch and the animal's living body has at once an ethical and ethological dimension, which are always inseparable in Derrida, it requires a change in the way we look at the animal towards a recognition of what could be called a haptic community between humans and animals, which signals towards the question of vulnerability as it is thought through by Derrida. It is precisely this ethical care which leads Derrida to give to this Aristotelian concept of 'coextensivity' its most radical signification. Indeed, whereas Aristotle separated life from death as the two poles of any

\footnotetext{
2 Jacques Derrida, On Touching - Jean-Luc Nancy, trans. Christine Irizarry (Stanford, CA: Stanford University Press, 2005), 47.

${ }^{3}$ La Vie la mort, thus spelled, was the title of a seminar that Derrida ran in 1975-76 - Trans.

${ }^{4}$ Derrida, On Touching, 53.
} 
living existence, Derrida seeks in this concept a way of making of the living animal a being which through touch is in permanent connection with life as much as with death. Put differently, the animal is a being which through touch permanently institutes the limits of its relation to life-death, a relation which can be interpreted according to a double movement of interiorization and expulsion which deserves some explanation inasmuch as it can introduce us to the problem of vulnerability in Derrida.

What should be understood by 'interiorization through touch'? Interiorization should be understood here as the fact that touch becomes in each living being a 'touching oneself': to touch is first to self-touch oneself. Thus, it is something like life which touches itself in the animal living being through the phenomenon of interiorization. To live is for each living being a touching oneself which makes them exist as such through this operation of transitivity of the living with regard to themselves. All existence turns out to be impossible and falls into nothingness, that is to say, death, without this vital necessity of 'self-touching oneself' which at the same time takes on an aporetic form since this 'self-touching' can only be at the same time a 'touching the other'. Hence as a consequence this opening of touch towards what Derrida calls an 'expulsion'.

What should be understood by 'expulsion' of this essential moment of life that touch is? By this 'expulsion' one should understand the necessity for the animal to exteriorize its touch in order to carry on existing while protecting itself against the risks inherent in this operation of going outside of itself which gives rise to this 'becoming tangible'. This 'becoming tangible' therefore signals towards the problem which Derrida's animal philosophy confronts: the question of the untouchable and therefore that of vulnerability. Thus, it is indeed this very term 'untouchable' which designates the aporia to which the question of touch is submitted in depth. Here is this aporia in all its complexity: if all animal life exists only through and in touch, whether it be a 'selftouching oneself' and/or a 'touching the other', we understand consequently that this opening to the other, to the touching which the other always is, constitutes a permanent threat, a risk intrinsic to its own existence as a living being, a threat and a risk which lie at the very heart of touch as the sense carrying the animal's vulnerability. But it is precisely this risk which is the condition of what Derrida, using a very strong term, calls 'spiritualization' of animal life, which is capable of producing 'a becoming intangible of the tactile body' between the touching and the touched. To put it otherwise, it is indeed through touch that the animal creates its own body whose life is always threatened by the other's touch, that is to say, the other of touch; hence the question of vulnerability which Derrida places at the centre of his animal philosophy via touch.

It is this aporia constitutive of touch which must be thought through and which makes of the animal a living being which can only touch itself in order to exist but which at the same time creates for itself a limit between an inside and an outside, a limit which could be called 'spiritual', in front of which the animal is placed in front of its finite existence, in front of its own finitude as well as in front of the other's. This is tantamount to saying still more radically and analytically that the animal's finite existence reaches it through touch as does the other's. It is therefore thanks to this tactile finitude that the other always becomes other only in relation to oneself, any encounter being based on touch as it creates limits inside the animal living being but also inside the relation between the human and non-human living being. Put otherwise, it is touch which traces the limit between me and the other, whether this 'me' be called animal or human, since such distinctions lose all conceptual relevance and ontological value in 
this animal philosophy. Without auto-affection, the animal's life is called into question and this very auto-affection allows any living being to welcome the other in them, hence vulnerability.

\section{Limit of/through Touch}

This limit is the possibility of spacing inside touch itself, which disseminates in relation to the other senses and in relation to whatever could space out or extend it. Basically, the limit instituted by touch lives only through and for this spacing and is capable of opening onto whatever might widen it, yet always under the law of extensivity which is one of the central elements in Derrida's animal philosophy when it takes the shape of a thinking about vulnerability:

[...] but this limit, here, puts touch and the other senses in touch, and thus confirms the quasi-transcendental privilege of the tactile - of spacing, in truth - and further, of spacing as what gives rise to techne and the prosthetic substitute. ${ }^{5}$

Spacing is the other abstract name for this atypical sense that touch is insofar as it instigates a limit from which an event in the life of the living occurs. Touch between man and the animal is truly the condition of their encounter without the latter having to transform either into fusion or identification, which both convey the illusion of immediacy, to which Derrida gives the name of 'immediate contiguity'. The point will be therefore to dissociate touch from immediacy: such is the deconstructive watchword which animates this animal philosophy as it

bids us to break with common sense as much as with a certain philosophical sense which has been dominant in the history of thinking about the animal in order to understand the importance of touch and its relation to the question of vulnerability, which acquires its full meaning in Derrida from that of touch.

Common-sense and the dominant philosophical sense are two major forms of what Derrida calls 'haptocentrism' as the privilege granted to the human hand in touch to the detriment of the existence of complex animal touch or, more exactly, of a sense of touch proper to any living being. There are indeed close connections between haptocentrism and anthropocentrism, among which the belief that touch would be merely an empirical manifestation of immediate sensibility. Now this does constitute the crucial point in the question of vulnerability in Derrida: namely, that no immediacy can exist in haptic sensibility for nothing exists in the life of the animal living being which could be reduced and be subjected to the concept of tactile sensibility. To put it yet more explicitly, touch as the fundamental phenomenon of animal life does not really allow itself to be circumscribed by empirical observation. Indeed, if the Derridean ban on immediacy plays such a key role, it is because it exists only in order to forestall the risks which would turn the sense of touch into a sense like the others. We must therefore attempt to have access to what we shall call 'the law of touch' with a view to going beyond the distinctions which have hitherto prevented the founding of a philosophy of animal touch in relation to vulnerability, distinctions which are based on the nature versus culture dualism. This foundational dualism in the thinking about the animal in the West is based on the separation of reality into two hermetically tight worlds, one of which would be subjected to a natural determinism enclosing the animal in nature, and

\footnotetext{
${ }^{5}$ Derrida, On Touching, 119.
} 
the other to a freedom supposed to be proper to man. We shall find other dualisms to be deconstructed further along this study.

\section{The Law of Animal Touch}

A constant obsession in Derridean deconstruction has been to go beyond the distinction between animality and humanity, in which many of our reflections on the animal question are still grounded. Such an overstepping is achieved through the existence of a law of touch. If indeed there is a law of touch which interrupts contact among the living, without being able to give it up entirely, this law exists before the metaphysical separation between man and the animal. Indeed, the immediacy which still too often controls our relation to the question of animal touch leads us to make of touch an act implying a 'natural' body which would be subjected to laws regulating its physiological and zoological functioning. In other words, touch would be fundamentally related to the animal's physical body. Now touch is not a question which has to do with physiology, which could thus be satisfied with some scientific observations. Touch cannot belong to even the most scientific ethology. Indeed, if touch merely amounted to this natural phenomenon which it gives the illusion of being, an objective knowledge of the scientific type would cope with it successfully. Now this knowledge is impossible for it is caught up in the inability to take into account what in touch is not reducible to touch, what in touch escapes its mere physical manifestation, namely, the 'fact' that touch exists only because there is non-touch, something which has to do with the untouchable at the very heart of touch. It is thus confirmed that touch is indeed the sense of paradox insofar as it permanently opens and closes to the other. It is the sense which lives only through the possibility of not touching the other. Put otherwise, it is this auto-affection as the fundamental law of touch which controls its own particular life and which makes of the former, against empirical and philosophical common sense, a sense which can never be reduced to an objective nature. More fundamentally, the law which animates the animal's touch is never to submit to what one calls 'nature' in the West, even to emancipate itself from it if one understands by nature the biological life kingdom.

Thus, if there is no nature of a biological order that dictates its law to animal touch insofar as it is precisely through touch that the animal emancipates itself from nature understood as determinism, the anteriority of touch also calls into question the categories of 'subject' and 'object', or still of 'patient' and 'agent', that is to say, those of a 'who' and a 'what' in a continuity which is at once tangible and non-tangible. This amounts to saying that the animal is at the same time and at once subject and object, who and what. Putting it in another way, in the experience of touch, the touching and the touched are no longer separable because the who and the what no longer hold: the one that touches becomes touching as much as touched, whether it be human or animal. The ultimate consequence of this is to deconstruct touch as a category of thought reserved to the human, which deconstruction operates through animality itself. Let us make more explicit this important point in order to better understand vulnerability in Derrida:

Now in this regard it is no longer possible to ask the question of touch in general, regarding some essence of touch in general, before determining the 'who' or the 'what,' the touching or touched, which we shall not too hastily call the subject or object of an act. There is not in the first place the sense of touch, followed by secondary modifications that 
allow the verb to be completed by a subject or a complement (that is, what touches whom or what, who touches whom or what). ${ }^{6}$

To say there is not 'the sense of touch' implies the consideration that there is basically in this phenomenon nothing but singularity, and this phenomenon or else event is endowed with the power to destabilise the life which animals are carriers of. The importance of the question of touch in relation to the problem of vulnerability is what this event that touch is permanently risks placing animal life in a position of object and of 'what', and in a position of 'subject' the human living being which thus exercises its sovereignty over animal life. This is why we must from now on ask ourselves if animal vulnerability does not find its primary source precisely in this radical dependency of animal life on touch.

\section{Animal Vulnerability as Unpower [impouvoir]}

It is in order to enable animal philosophy to break out of a dominant tradition that Derrida has sought to think through the question of vulnerability. This dominant tradition lies in subordinating the question of the animal to that of power by instituting man at the top of this power. This anthropocentrism which defines much of western philosophical tradition as well as all culture is probably at the origin of the impossibility for this very tradition and culture to recognize and take seriously the question of vulnerability which Derrida places as the principle behind his animal philosophy:

[...] in the dominant tradition of how the animal is treated by philosophy and culture in general, the difference between animal and human has always been defined according to the criterion of 'power' or 'faculty,' i.e. the 'being able to do [pouvoir faire]' or the inability to do this or that(man can speak, he has that power, the animal does not have the power of speech, man can laugh and die, the animal can neither laugh nor die, itis not capable of its death, as Heidegger literally says: it does not have the power (können) of its death and to become mortal, etc. $)^{7}$

\section{The Derridean Definition of Vulnerability}

It is therefore against this dominant tradition that the question of vulnerability arises in Derrida's thinking. At stake is the deconstruction of this tradition which violently reduces animal life to the sole question of 'power' and 'non power' in order to introduce that of life and the vulnerability which defines it, namely, the question of animal suffering. If after all Derrida has in fact written little about vulnerability, the little he says is decisive in his thinking about animality, which rests on the fundamental thesis that one must start from vulnerability in order to understand what animality is and therefore any animal life. More exactly, all his animal philosophy stems from the idea, unique in continental and contemporary philosophy, that animal life (common to animals and humans) is definable by vulnerability defined as 'possibility without power'. What does this mean? What are the links between vulnerability, power and suffering? Here is the definition of vulnerability proposed by Derrida in his last seminar

\footnotetext{
${ }^{6}$ Derrida, On Touching, 68-9.

7 Jacques Derrida, The Beast and the Sovereign, Volume II, ed. Michel Lisse et al., trans. Geoffrey Bennington (Chicago and London: The University of Chicago Press, 2011), 243.
} 
dedicated precisely to the question of the animal and to that of the links between ethology and ethics:

the power to suffer is in that case the first power as non-power, the first possibility as nonpower that we share with the animal, whence compassion. It is from this compassion in impotence and not from power that we must start when we want to think the animal and its relation to man. ${ }^{8}$

Derrida therefore defines animal life as a life which is deeply characterised as a 'power to suffer', far from a traditional conception of philosophy which as we have said defines life as power reserved to man and lying basically in the power to act on himself by way of cognitive faculties. This is what Derridean deconstruction has always called 'logocentrism', which is therefore indeed the reduction of life to intellectual thought or, more exactly, the subjection of animal life to reason and therefore to the logos. Thus, the question of vulnerability intervenes also as a major element in the deconstruction of this logocentrism which turns out to be incapable of taking the animal point of view into account. It is this most important problem which Derrida explains in the few pages of his book The Animal That Therefore I Am which are dedicated to vulnerability:

'Can they suffer?' asks Bentham, simply yet so profoundly.

Once its protocol is established, the form of this question changes everything. It no longer simply concerns the logos, the disposition and whole configuration of the logos, having it or not, nor does it concern, more radically, a dynamis or hexis, this having or manner of being, this habitus that one calls a faculty or 'capability,' this can-have or the power one possesses (as in the power to reason, to speak, and everything that that implies). ${ }^{9}$

The problem of vulnerability as Derrida thinks it through makes an explicit reference to Bentham, who was the first in the history of philosophy and culture to place the question of animal suffering at the heart of his preoccupations. Yet despite the obvious affinity between the two thinkers, Derrida develops another reading, which aims at least at three objectives which define his animal philosophy. One of the first, and not one of the least - let us inset on it for it seems to us to be crucial - affords him the possibility to tackle frontally this dominant philosophical tradition which has never recognized to the animal the possibility of vulnerability and therefore of suffering. Indeed, the question of the 'animal's power to suffer' (Derrida's phrase) allows him to deconstruct in depth the dominant animal philosophy which rests on the logos as anthropocentric philosophy: it is therefore first a deconstruction of this logocentric animal philosophy which revolves around the question of knowing if animals have the logos, if the logos is available to animals or not.

But the question of vulnerability allows him to go still further in this deconstruction of logocentric animal philosophy by deconstructing other important concepts such as those of dynamis and hexis which all seek to think through the animal question in terms of 'power', which Derrida reformulates by speaking of 'can-have' or else of 'power one possesses', and which he will illustrate through common phrases such as 'power to reason', 'power to speak' and 'everything that that implies'. As a consequence, Derrida overturns the dominant interrogation about animality arguably by

\footnotetext{
${ }^{8}$ Derrida, The Beast and the Sovereign, 244.

9 Jacques Derrida, The Animal That Therefore I Am, ed. Marie-Louise Mallet, trans. David Wills (New York: Fordham University Press, 2008), 27.
} 
relying on Bentham, yet while insisting on the necessary deconstruction of concepts like 'logos' and 'power', which signal towards the problem of the faculty of which animals are supposedly devoid and deprived, but especially while introducing a novel idea with important consequences on the animal question itself and with fundamental theoretical issues at stake. It is the question of animal unpower, a Derridean name for vulnerability, which is defined as follows:

[Bentham's]question is disturbed by a certain passivity. It bears witness, manifesting already, as question, the response that testifies to a passibility, a passion, a not-being-able. The word can [pouvoir] changes sense and sign here once one asks, 'Can they suffer?' Henceforth it wavers. What counts at the origin of such a question is not only the idea of what transitivity or activity (being able to speak, to reason, etc.) refer to; what counts is rather what impels it toward this self-contradiction, something we will later relate back to auto-biography. 'Can they suffer?' amounts to asking 'Can they not be able?' And what of this inability [impouvoir]? What of the vulnerability felt on the basis of this inability? What is this non power at the heart of power? What is its quality or modality? How should one take it into account? What right should be accorded it? To what extent does it concern us? ${ }^{10}$

Let us begin by asking ourselves some semantic questions, in order to make explicit the importance of the Derridean concept of unpower, regarding the terms used by Derrida with a view to elaborating his conception of vulnerability, while wondering about the words 'passivity', 'passibility' and 'passion' in the sentence 'The question is disturbed by a certain passivity. It bears witness, manifesting already, as question, the response that testifies to a passibility, a passion, a not-being-able.' What does it all mean? This means that Bentham's question is first analysed by Derrida as a problem related to a thought about testimony since Derrida speaks of a 'response that testifies', an expression which indicates that vulnerability, far from being a theoretical, abstract concept, far from stemming from an intellectual thinking about animality, signals directly towards an empirical datum in the first instance and which can be observed all the more since Derrida here reiterates the same idea several times with four synonymous, yet never identical terms: 'passivity', 'passibility', 'passion' and 'nonpower'. Each of these terms says something singular about vulnerability, but what Derrida insists on, through this alleged repetition, is that vulnerability is first a question of testimony insofar as it is the very existence of this animal vulnerability which depends on this testimony, a dependency which underscores even further this vulnerability which thoroughly defines animal life. In this respect, this vulnerability cannot be content with being an empirical question for it is not enough to see the phenomenon to describe it, to analyse it and even less to understand it. Put differently, what can eb seen and therefore what one can testify to after the fact, if and only if one resorts to these four concepts which are close to one another without ever being identical, is this possibility in which animals live, which lies not only in suffering (a more or less empirical, observable datum) but more essentially in not being able not to suffer (a non-empirical, non-observable datum in effect).

It is their very life which is marked by this impossibility of not being able not to suffer in the relations they have with humans, as if the latter had withheld power from them in order to replace it with non-power as passivity and therefore as receptiveness to

10 Derrida, The Animal That Therefore I Am, 27-8. Trans - I have substituted 'passibility' to the translator's original choice of 'sufferance' to keep the etymologically nexus with the other terms used by Derrida. 
suffering. Vulnerability would therefore be this state of unpower in which humans have placed animals, a state which not only produces suffering but also the impossibility of recognizing it as such, hence the importance of the notion of testimony. Without testimony, vulnerability would be invisible and the Derridean work on words allowing for this testimony is not a conceptual or intellectual luxury, but like a vital necessity in order to see otherwise this vulnerability and this unpower, which are indeed abstract notions which only a work on words will enable to escape from blinding abstraction.

The other new element to be underlined in Derrida's thinking about vulnerability rests on a radical inversion of the word 'power' to re-semanticize it with a view to thinking through better the question of animal vulnerability. Indeed, Derrida says, the word 'power' (can) changes meaning here as soon as one says 'can they suffer?' The word 'power' analysed here by Derrida no longer merely has to do with the question of what he calls 'transitivity' or 'activity', terms which until now have invented the intellectual and theoretical frameworks of how the animal question was understood in the West, in connection with what one could name 'agentivity' even though Derrida does not use the concept. More exactly, what is at stake in our opinion is for Derrida to break out of a false opposition between passivity and activity, patient and agent, to give way to what he calls a 'self-contradiction' which can be analysed as the existence, at the heart of any singular animal life, of an opposition, probably constitutive of any animal singularity, between two opposite yet inseparable forces named 'power' and 'non power' either of which cannot be thought of without taking the other's existence into account, well beyond the dualism between passivity and agentivity. The Derridean thesis in its ethical and ethological radicality consists in saying that there is in any animal life some non-power at the heart of the power proper to each singularity. It does not mean therefore that non-power prevails over power but rather that there is nonpower at the very heart of the animal's power over oneself. The question of touch as seen in the first part allows us to understand this difficult point: touch is the animal's power over oneself, a fundamental power of its existence but one that can be denied to it to the point of making it into a non-power from which animal suffering becomes possible.

What is fundamentally at stake in Derrida's thinking about vulnerability is never to reduce the life of the animal living being to one of the two opposite poles to which it has always been reduced: either to agentivity, which Derrida calls 'activity', which is always thought through as in need of measuring itself against human agentivity posed as an absolute norm, or to passivity, which has always been thought through as negative figure of the life of the non-human living being, the absolute norm remaining forever still that of the human living being.

The question of knowing whether animals suffer also amounts to that of knowing whether the relations they have with humans can produce anything else than suffering and if they are able not to suffer as long as humans are the only ones who determine the life of animals. Another subsidiary question which stems from Derrida's reformulation of the problem of vulnerability is that of knowing whether this vulnerability of animals is not in part provoked by the violence of domestication. In other words, the question Derrida asks amounts to knowing whether another type of non-violent relations between humans and animals, producing no vulnerability, is possible. This entails giving a political spin to the question since it is about knowing how to introduce power into this animal unpower if one takes up their point of view. Regardless of the question of knowing how to break out of animal vulnerability, there is no doubt for Derrida that this 
unpower at the heart of any animal life compels us to think through the animal question first as a question about sensibility in order then to be able to extend it to other political issues at stake, without any ontological separation in reality coming in between the sensible and the political according to Derrida's perspective: 'And what of this inability [impouvoir]? What of the vulnerability felt on the basis of this inability?' Why does Derrida say about vulnerability that it is felt from this inability or unpower? If one starts from the idea that vulnerability is provoked by the power of man over animals, then this vulnerability, as the introduction of non-power into the life of the animal, turns out to be a deliberate choice by man consisting in withdrawing power from the animal in order to reappropriate it.

\section{A New Conception of Animal Suffering}

Derrida defines animal vulnerability most rigorously: 'Being able to suffer is no longer a power; it is a possibility without power, a possibility of the impossible.' ${ }^{11}$ This is an important definition of vulnerability for it connects suffering and vulnerability, and signals a break with Bentham. Indeed, the fact of being able to suffer is in reality not a power, contrary to what the verb 'can' indicates in Bentham's question, which is not really about the animal's power but rather about the possibility of animal suffering. Animal suffering is the possibility of animal life and turns out to be, according to Derrida's perspective, what precisely distances the animal from any power over itself and the world. Put otherwise - and herein lies the ethical dimension of Derrida's reading of Bentham - the possibility of animal suffering is the opposite of the animal's power over itself. This amounts to saying that when the animal suffers, it no longer has any power over its own life and its power over itself is non-existent. A suffering animal is therefore a vulnerable animal in the sense that any power over itself has been violently withdrawn from it. To make an animal suffer is therefore to take away from it any power over itself and thus to increase its vulnerability to suffering.

Animal suffering as a possibility without power enables us to understand better the opposition which structure Derrida's thinking about vulnerability, between 'possibility' and 'power' To say about animal suffering that it is a possibility without power amounts to rethinking animal vulnerability. Indeed, if vulnerability, expressed here by animal suffering, is a possibility of animal life, it means not only inscribing the question of suffering at the centre of that of vulnerability - this inscription is one of the important characteristics of Derrida's animal philosophy - but also, as possibility, it means fundamentally underlining the fact that it is basically nothing but one of the possible manifestations of animal life which can therefore not be reduced to this vulnerability when it takes the form of suffering. One finds again once more, but according to another configuration, this opposition between two forces opposed to each other in animal life, the opposition between 'possibility' and 'power'. Our interpretative hypothesis is that, in relation to the question of vulnerability, Derrida also wants to deconstruct this opposition between power and possibility insofar as this duality too separates animals from humans arbitrarily and artificially, making of animal life the only place for the possibility of suffering (great vulnerability) and of human life the place for the power over oneself (lesser vulnerability). Now this dualism is radically deconstructed by Derrida in order to insist on the continuity which is common to all,

\footnotetext{
${ }^{11}$ Derrida, The Animal That Therefore I Am, 28.
} 
which is thought through under the concept of finitude inseparable from that of animal vulnerability. A finitude which is inseparably made up of power and non-power, whose mixture depends fundamentally on relations of power, and therefore of domestication, between human and non-human living beings.

\section{Conclusion: Ethics and Politics of Animal Vulnerability}

If Derrida's invitation to think through the relations between humans and animals from animal vulnerability is important to us, it is because, as we have tried to show, one admittedly seldom finds in western philosophy a thinking about vulnerability in which ethological, ethical and political issues are so radically at stake. There is certainly a thinking about animal vulnerability in Derridean deconstruction in which it must be acknowledged readers of Derrida have shown very little interest. This thinking is arguably not the only one capable of offering what is needed in order to free animals from the violence to which they are subjected, but it allows for the creation of ethical and political conditions for new relations with animals. If vulnerability is truly a 'possibility without power' of the animal or else a 'non-power' within power, Derrida's fundamental contribution to the reflection on vulnerability is to have introduced the immense question of the animal's power into its heart in order to overhaul it from the ground up in relation to Bentham, not the question of power over the animal, but rather that of the power which the animal can have over its own life. Such is the novelty to be taken into account from now on in order to elaborate new links within the framework of a domestication deconstructed at the service of animal life.

Translated by Laurent Milesi

\section{Bibliography}

1. Aristotle. De Anima. Translated with an Introduction and Commentary by Christopher Shields. Oxford; Clarendon, 2016.

2. Derrida, Jacques. The Animal That Therefore I Am. Edited by Marie-Louise Mallet. Translated by David Wills. New York: Fordham University Press, 2008.

3. Derrida, Jacques. On Touching - Jean-Luc Nancy. Translated by Christine Irizarry. Stanford, CA: Stanford University Press, 2005.

4. Derrida, Jacques. The Beast and the Sovereign, Volume II. Edited by Michel Lisse et al. Translated by Geoffrey Bennington. Chicago and London: The University of Chicago Press, 2011. 


\section{Vulnerabilitatea vieții animale în filosofia lui Derrida}

\section{Rezumat}

Derrida a fost preocupat de problematica animalităţii de la începutul până la sfârşitul vieții. Animalul se regăsește de la primul la ultimul său text, dar prezența acestuia este întotdeauna supusă unor noi formulări și explicații, ca și cum problematica animalului în gândirea lui Derrida este inepuizabilă: într-adevăr, nimic și nimeni nu pare a o epuiza... Analiza noastră ia această inepuizabilitate ca punct de plecare pentru a examina unul dintre ultimele concepte relucrate de Derrida către sfârşitul vieții, și pe care cititorii l-au ignorat pațial: conceptul de vulnerabilitate. Acest articol sondează posibilitatea acestui concept de a ne permite să recitim în profunzime textele relevante ale lui Derrida ca un corpus unificat de opere, dincolo de pretenția de a îi epuiza sensurile. 